Article

\title{
Framework of National Non-Structural Measures for Flash Flood Disaster Prevention in China
}

\author{
Dongya Sun ${ }^{1}$, Dawei Zhang ${ }^{1,2, *}$ and Xiaotao Cheng ${ }^{2}$
}

1 Research Center on Flood and Drought Disaster Reduction of the MWR, Beijing 100038, China; E-Mail: sundy@iwhr.com

2 State Key Laboratory of Simulation and Regulation of Water Cycle in River Basin, China Institute of Water Resources and Hydropower Research, Beijing 100038, China; E-Mail: chengxt@iwhr.com

* Author to whom correspondence should be addressed; E-Mail: zhangdw@iwhr.com; Tel.: +86-10-68781951; Fax: +86-10-68536927

Received: 6 February 2012; in revised form: 22 February 2012 / Accepted: 12 March 2012 / Published: 19 March 2012

\begin{abstract}
In recent years, disasters caused by flash floods with many casualties have occurred frequently in China. In order to effectively prevent flash flood disasters, the State Council approved the National Flash Flood Control Planning (NFFCP) in 2006. In this planning, non-structural measures are recommended as the first step to be adopted in the prevention of flash floods, debris flow and landslide disasters caused by heavy rainfall. In order to effectively build up a comprehensive non-structural measure system for flash flood disaster prevention, the Ministry of Water Resources has asked the local authorities to conduct studies in 103 pilot counties aiming to explore practical schemes. Based on the experience from these pilot counties, the construction of non-structural measures on flash flood disaster prevention for 1836 counties was officially initiated in 2010 . The contents of non-structural measures for flash flood disaster prevention at county level include eight aspects. This paper will systematically illustrate the main contents of this national project for the construction of non-structural measures for flash flood disaster prevention in China. This work could provide a reference for other countries and regions in terms of flash flood prevention.
\end{abstract}


Keywords: flash flood disaster prevention; non-structural measures; monitoring; warning; China

\section{Introduction}

The flash floods referred to occur after heavy local rainfalls, often in mountainous areas. They are characterized by a quick rise of water levels causing a threat to the lives of those exposed. The time available to predict flash floods is limited. Flash floods often induce landslides and debris flows leading to severe damage and casualties in local areas. Due to the complex process of flash flood formation, the complicated characteristics of river basins in mountainous and hilly areas and the uncertainty of short-duration heavy rainfalls, flash flood prevention is a worldwide problem posing a great challenge. Many countries and regions attach great importance to the work of flash flood control. In the United States, flash flood warnings and watches are issued by local NWS Weather Forecast Offices (WFOs), which base the information on the comparison of rainfall amounts with flash flood guidance (FFG) values. FFG procedures were first formed in the 1990s. FFG was established by regional River Forecast Centers (RFC) and provided to local WFOs for flash flood forecasting [1]. In the European Union, a FP6 project titled FLASH ran from 2006-2009 in an attempt to improve the knowledge of historic flash floods in the Mediterranean region, while trying to improve forecasts of heavy precipitation events [2].

Compared to advanced countries, the research on flash flood disasters started relatively late in China. In recent decades, along with the rapid social and economic development as well as increasing losses caused by flash flood disasters, the issue of flash flood disasters has attracted wide attention in the whole society. Some scholars carried out thematic studies on this topic and the prevention work of flash flood disaster has progressed step by step. Particularly since 2000 — with the development of the national economy and infrastructure construction and due to increasingly serious disasters caused by flash floods - China has increased inputs into the research on flash flood disasters and their prevention. After some endeavors in recent years, a set of methodologies on flash flood disaster prevention featuring Chinese characteristics has been established. Construction of non-structural measures on flash flood disaster prevention was carried out in 1836 counties nationwide.

This paper first introduces the basic situation of flash flood disasters in China, and then focuses on the Chinese government's efforts to establish non-structural measures regarding flash flood disaster prevention in recent years.

\section{Basic Situation of Flash Flood Disasters in China}

Mountainous and hilly areas account for two thirds of the land area in China, among which the prevention area of flash flood disasters reaches 4.63 million $\mathrm{km}^{2}$ (see Figure 1), involving a population of 560 million. The priority prevention area equals $970,000 \mathrm{~km}^{2}$, affecting a population of 130 million. The priority prevention area can be subdivided into a first-grade prevention area and a second-grade prevention area according to the occurrence frequency of flash floods, geology and topographical conditions and the socio-economic situation. 
In recent years, the characteristics of flood disaster losses have changed in China. The most outstanding change is that the percentage of casualties caused by flash floods remains high and holds an increasing trend, which has become a significant issue of the flood control and disaster mitigation task. In 2010 China witnessed particularly serious flash flood disasters, with 3887 people dead or missing. Representative events include: Massive debris flows that occurred on 7 August in Zhouqu, Gansu Province, leading to 1,500 people dead and 265 people missing; massive debris flows that occurred on August 18 in Puladi Town, Gongshan County, Yunnan Province, leading to 92 people dead or missing.

Figure 1. Zoning map of prevention area of flash flood disasters in China.

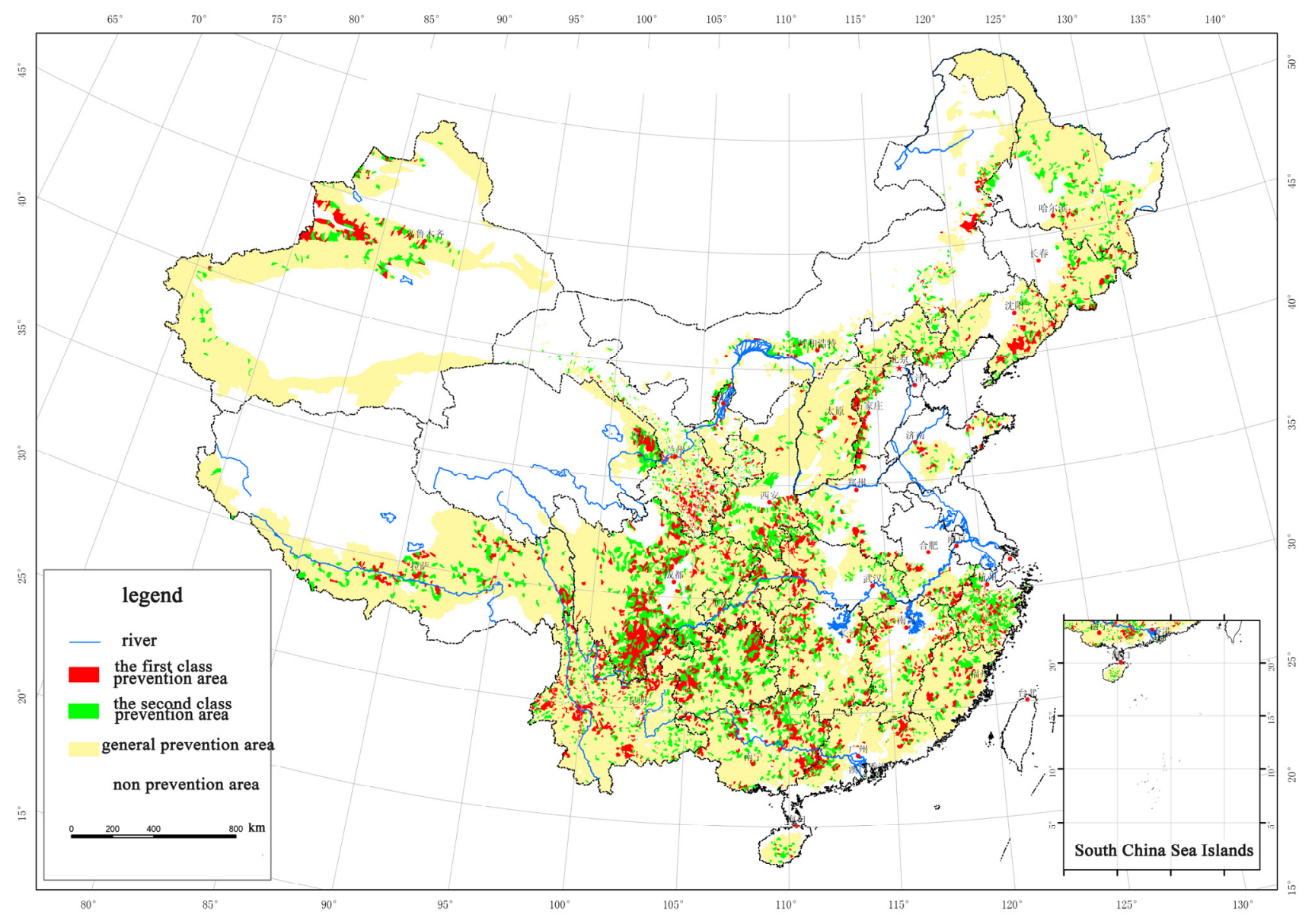

According to the statistical data, the proportion of deaths caused by flash flood disasters to those caused by flood disasters from 2004 to 2010 were $78 \%, 84 \%, 71 \%, 75 \%, 80 \%, 80 \%$ and $90 \%$, respectively (shown in Figure 2). Flash flood disasters have become the major reason for casualties and have severely restricted the social and economic development in mountainous and hilly areas. It is imperative to strengthen the preventive work of flash flood disasters [3]. 
Figure 2. Proportion of deaths caused by flash flood disasters compared to those caused by flood disasters.

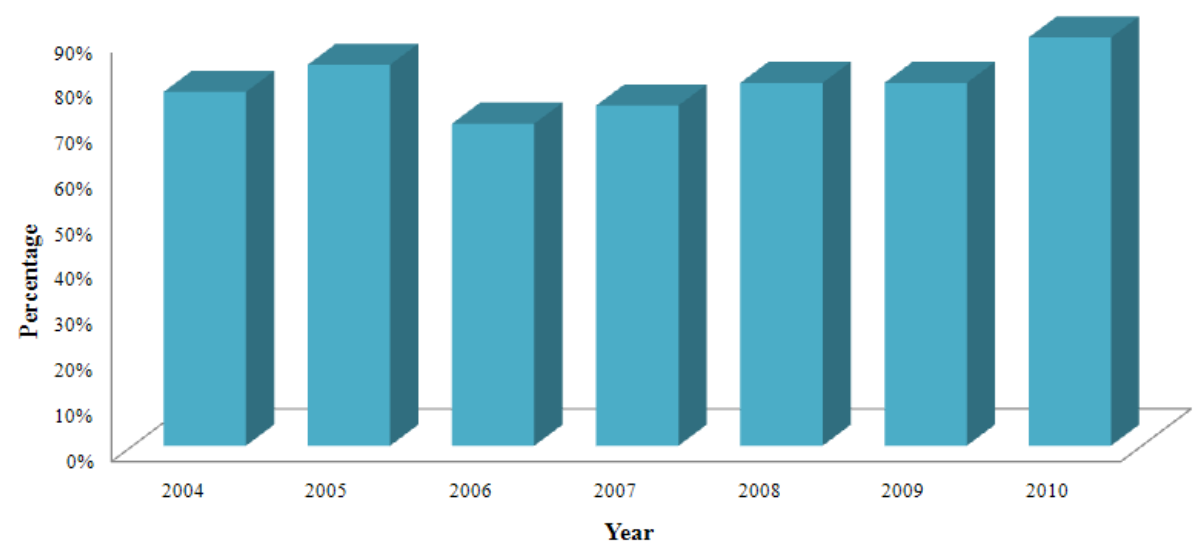

\section{National Flash Flood Control Planning (NFFCP) and Pilot Project}

The Chinese government has attached great importance to the issue of flash flood disasters. In 2005, the Ministry of Water Resources, together with the Ministry of Land and Resources, China Meteorological Administration, the former Ministry of Construction and the former State Environmental Administration, compiled the National Flash Flood Control Planning (NFFCP)[4], which is the first thematic plan aiming at flash flood disaster prevention. Covering 1836 counties of 29 provinces, autonomous regions and municipalities, the planning adheres to the principle that non-structural measures are given priority while planning structural measures. A structural measure is seen as any physical construction to reduce or avoid possible impacts of hazards, or any application of engineering techniques to achieve hazard-resistance and resilience in structures or systems (for example building levee, embankment, etc.). Non-structural measures are defined as any measures not involving physical construction that use knowledge, practice or agreement to reduce risks and impacts, in particular through policies and laws, public awareness raising, training, education etc. With the guidance of this principle, a disaster prevention system is established including monitoring, communication, forecasting and warning. In October of 2006, the State Council officially approved the NFFCP and stipulated that - with the short-term planning projects as the priority and timely personnel evacuation and casualty reduction as the objectives - the construction of pilot projects should be sped up in priority prevention areas of flash flood disasters by adopting effective non-structural measures such as rainfall monitoring and construction of warning systems. On top of that, knowledge dissemination and management should be strengthened, the general public's awareness on disaster prevention and mitigation should be improved, and the masses' capacity of self-prevention, self-rescue and mutual assistance should be promoted to set up a monitoring and prevention system enforced by the masses themselves.

In order to actively explore effective ways and means for flash flood disaster prevention, and to accumulate experience for the implementation of the NFFCP, the Chinese government set aside special funds in the budget for pilot projects focusing on non-structural measures for flash flood disaster prevention in 103 counties of 30 provinces (autonomous regions and municipalities) in 2009.

The pilot projects of flash flood disaster prevention mainly focused on non-structural measures, such as monitoring and warning facilities, warning platforms, evacuation plans, organizational systems, 
knowledge dissemination, training and exercises. These above-mentioned non-structural measures could be further elaborated as follows:

(1) define the safety areas and hazardous areas;

(2) determine the critical rainfall(water level) that will trigger the occurrence of flash floods;

(3) adapt the monitoring and warning equipments;

(4) comprehensively equip the counties with the necessary warning facilities;

(5) develop the warning platform of flash flood disasters at the county level by using GIS and data bases as well as large scale electronic maps;

(6) establish the hierarchical responsibility system consisting of five levels: county, town, village, production group and household. Clarify the duty of each level and form a defense system in which the monitoring and prevention activities are enforced by the masses;

(7) formulate preparedness plan to guide the disaster prevention and avoidance activities;

(8) carry out knowledge dissemination, training and exercise activities to promote the awareness and capacity of the grass-roots cadres and masses on disaster prevention and emergency response.

Based on the actual situation, all the pilot counties of the 30 provinces have successfully accomplished the task with explorative efforts and positive innovation. A number of valuable experiences and practices are summarized below:

(1) Intensify the construction of monitoring sites and strengthen information sharing. Establish a rainfall and water level monitoring network that basically covers all villages and construction groups within the pilot regions by combining automatic telemetry and simple artificial observation. Provide timely and accurate rainfall and stream water level information and realize the information auto-writing into database.

(2) Adopt various measures to distribute warning messages timely and instantly. Through adopting traditional means and developing new ones, each pilot county worked out many ways and means to distribute and send warning messages in order to ensure that they were received by each town, village, construction group and each person in the flash flood disaster prone areas.

(3) Conduct dynamic monitoring and analysis of warning messages timely in order to effectively improve the commanding and decision-making capacities of defending flash flood disasters in the grass-roots areas. Each pilot county established a platform for warning of flash flood disasters. The telemetry rainfall and water level information can be automatically written into the database, and the warning message can be released automatically or manually through the platform.

(4) Improve organizational structure and assign responsibility to make sure that the prevention work of flash flood disasters was effectively and orderly carried out. Each pilot county formed a relatively perfect responsibility network of flash flood disaster prevention in the grass-roots areas by establishing the responsibility system of flash flood disaster prevention, setting up the five hierarchy responsibility system that covers the level of county, town, village, production group and household, clarifying the organizational structure and responsibilities of each level, and forming a wonderful defense system in which the monitoring and prevention activities were enforced . 
(5) Optimize the plan system of flash flood disaster prevention in the grass-roots areas. Through overall investigation and research, each pilot county formulated or optimized the preparedness for flash flood disasters at the county, town and village levels in accordance with guidelines issued by the Office of State Flood Control and Drought Relief Headquarters (SFDH), which provided powerful guidance for conducting the work of flash flood disaster prevention.

(6) Strengthen knowledge dissemination, training and exercise activities to promote the masses' awareness of disaster prevention and avoidance, and their capacity on self-rescue and mutual assistance. By carrying out various forms of publicity, training and exercise activities at different levels, the knowledge of flash flood disaster prevention was rooted in the people's heart.

(7) Lay a sound technical foundation for the extension and popularization of the pilot projects to a large scale. The Ministry of Water Resources developed series of technical documents about project construction and management. Moreover, the Water Conservancy and Flood Control Department also formulated a series of systems and methods regarding project construction and management while carrying out pilot projects on different levels. On that basis, a group of intellectuals were involved that hold a good understanding of both the monitoring and warning system of flash flood disasters and project construction management. On top of that, many monitoring and warning facility manufactures and software development companies have accumulated experience, which will provide sound technical support on extending the pilot projects to a large scale.

(8) Use the pilot projects to vigorously drive the project construction and implementation on a large scale. The pilot projects created a good demonstrative effect and laid a sound fundament for constructing non-structural measures for flash flood disaster prevention in the whole country.

\section{Development of Non-Structural Measures for Flash Flood Disaster Prevention at County Level in China}

On the basis of the pilot project construction, the Ministry of Water Resources, together with the Ministry of Finance, the Ministry of Land and Resources and China Meteorological Administrative, organized video conference in November 2010 to officially initiate the construction of non-structural measures for flash flood disaster prevention at county level nationwide. With the purpose of improving the capacity of flash flood disaster prevention, minimizing personnel casualties and property loss as well as avoiding the occurrence of massive injury and death particularly, it was planned to initially establish the non-structural measures system of disaster prevention that mainly focuses on the monitoring and warning aspects in 1,836 counties that had suffered from flash flood disasters within the past three years.

Regarding a county as the basic unit for the construction of non-structural measures on flash flood disaster prevention, the flood control department also gradually established corresponding systems on central, provincial and municipal levels in order to receive the monitoring and warning information of flash flood disasters timely and to provide support for decision making. The overall structure is shown in Figure 3. 
Figure 3. Overall structure of non-structural measures construction for flash flood disaster prevention nationwide.

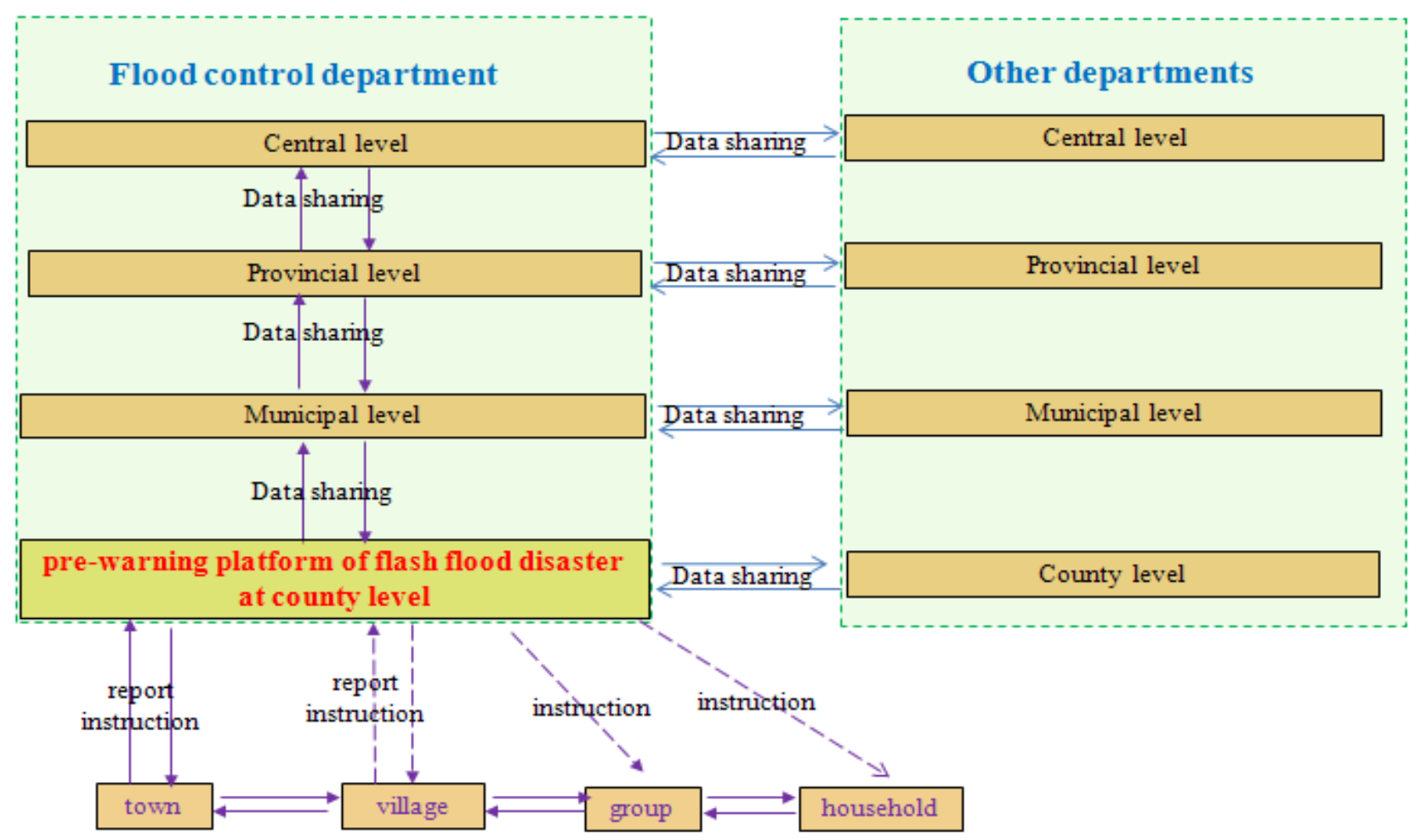

The major content of the non-structural measures construction for flash flood disaster prevention is as follows:

(1) Comprehensive investigation. Investigate the natural, social and economic situation, the population distribution situation, the types of flash flood disasters, historical flash flood disasters, the populations threatened by flash flood disasters and the distribution of major economic facilities in all small river basins.

(2) Risk assessment and risk area delineation. Based on the investigation results, define hazardous areas and safety areas within the flash flood disaster prevention area. The delineated area was then plotted on the maps used to prepare by considering the villages and small river basins as the basic unit.

(3) Determination of preparedness parameters and their magnitudes, such as critical rainfall and water levels. Based on historical records of rainfall and flash flood disasters, determine preparedness parameters and their magnitudes (e.g. critical rainfall and water levels) for each small river basin and village with consideration of topography, vegetation and soil type. This kind of threshold setup is very difficult. At a primary stage, the critical values are determined by experience based on historical disaster events or numerical analyses using distributed hydrological models. This could be reviewed and improved during practical implementation along with the accumulation of monitoring data in small watersheds in long time series.

(4) Construction of monitoring systems including automatic rainfall and water level monitoring instruments, simple rainfall and water level measurement devices used by local residents. At 
the same time, improve the monitoring properties by making full use of the existing monitoring instruments built by meteorological departments and hydrological departments.

(5) Construction of warning system platform at county level. The platform has the function of basic information inquiry, real-time inquiry of hydrological data from the monitoring system, hydrological forecasting, warning message dissemination and system management. The platform software will assess the monitored rainfall or water level data and compare this with pre-determined critical values corresponding to different warning grades. If the critical values are exceeded, text messages will be automatically sent to orderly individuals or/and the broadcast equipments in villages by using GPRS/GSM communication networks. The broadcast equipment can transform the text messages into sound signals and broadcast them to the public. It is also operational that the orderly individuals call the broadcast equipment and their phone call can be broadcasted to the public.

(6) Equip with necessary warning facilities. In addition to traditional ways such as hand cranking alarm, gong and whistle, warning facilities also include telephone, fax, text message, radio broadcast, television, etc.

(7) Establish a community-based defense system for disaster prevention in which the man-observed rainfall or water level monitoring and prevention activities are enforced by the masses themselves. Set up the five hierarchy responsibility system that covers the level of county, town, village, production group and household. Improve the commanding organization at town village level and clarify the responsible personnel and corresponding duties at different levels.

(8) Formulate the preparedness of flash flood disaster in accordance with the Guideline for the Compilation of Flash Flood Disaster Prevention Plan issued by the SFDH [5]. Carry out knowledge dissemination, training and exercise activities.

The investment for each county was six million Renminbi (RMB) shared by the central government and local government. In 2010 and 2011, the central government issued 3.8 billion subsidies to support the development of non-structural measures on the flash flood disaster prevention in 1,100 counties. In 2012, the remaining 736 counties will complete the construction of non-structural measures.

The SFDH as the project management agency actively took all efforts to promote the implementation of the project. For example, it formulated several technical guidances, such as the Technical Requirements on the Development of Warning System for the Flash Flood Disaster Prevention at County Level [6], and the Guideline for Compiling Implementation scheme of Non-structural Measures Construction for the Flash Flood Disaster Prevention at County Level [7]. The SFDH also organized the inspection meeting and developed the National Management Method on Non-structural Measures Construction for the Flash Flood Disaster Prevention at County Level [8]. Currently, the SFDH is setting up a website of national flash flood disaster prevention (www.qgshzh.com) to introduce the most current project situation [9].

\section{Preliminary Achievements-A Case Study}

Currently, the projects developed in 2010 have been progressing smoothly and are in full implementation throughout the country. The projects developed in 2011 will be finished before the flood season in 2012. In this year's flood season, Hunan Province, Yunnan Province, Jiangxi Province 
and Hubei Province distributed warning information timely by using non-structural measures systems recently completed or under development when fighting against flash flood disasters. The masses in the threatened areas were evacuated in advance and significant benefits were achieved. Following, a case study of Shennongjia forest region was given.

The Shennongiia forest region with an area of $3,253 \mathrm{~km}^{2}$ is located in the northwestern corner of Sichuan and Hubei Province. There are a total of 317 streams in the region and the confluence area of 15 streams exceeds $50 \mathrm{~km}^{2}$. All the streams originate in the territory of the district and they are all mountainous rivers. There are eight towns and 66 villages in this region.

Flash flood disasters have always been severe in this area. Therefore, the non-structural measures construction for flash flood defense had been initiated. The non-structural measures mainly include the construction of monitoring and warning systems, formulating preparedness plans, establishing a community-based defense system, flash flood control knowledge dissemination, training, etc. Specifically, besides the warning system platform, 77 simple rainfall measurement devices, 21 automatic rainfall monitoring instruments and three automatic water level monitoring instruments were installed. Detailed preparedness plans for flash flood disasters were established for eight towns and 66 villages. Various methods were used for knowledge dissemination and training such as meetings, broadcast, TV, website, paper, billboards, brochures, wall charts, CDs, cards, etc. Using these means, the awareness and capacity of withstanding risk of the local residents were improved. Everyone is now aware of the serious consequences potentially caused by flash floods and knows when and how to evacuate to a safe place.

The completed monitoring and warning system played an important role in the flood season of 2011. From 3:00 am on August 22 to 8:00 am on August 23, the Shennongjia forest region was hit by a heavy rainstorm. With the three-hour rainfall exceeding $100 \mathrm{~mm}$, the total rainfall was $270 \mathrm{~mm}$, being the maximum of the past 58 years since the construction of an existing hydrological station. The storm centre was located in the southern area of the forest region that covers four towns, i.e. Muyu Town, Hongping Town, Jiuhu Town and Songluo Town. The real-time rainfall data of automatic rainfall monitoring instruments were transmitted to the warning platform through a GSM/GPRS network. Three hours after the beginning of rainfall, the cumulative rainfall exceeded the presupposed critical rainfall. Then the warning beep and red flashing signals were automatically launched by the platform. The local flood control department instantly sent the warning messages using the platform and at the same time notified the responsible personnel of towns in the hazardous areas by telephone. Because of the timely warning, the potentially affected 79,427 people of 28,631 families in 327 villages were evacuated in advance following the preparedness plan. Due to these efforts, no person was injured or died. For the residents suffering from flash flood disasters, the system of non-structural measures for flash flood disaster prevention has become a real 'umbrella for life protection'.

\section{Conclusions}

Flash flood disasters occur frequently over a broad area in China. Due to the features of sudden occurrence and severe damage as well as difficulties in warning and prevention, flash floods lead to significant damages to people's life safety, infrastructure and eco-environment. The Chinese government attaches great importance to flash flood disaster prevention. In 2006, the first thematic plan aiming at the flash flood prevention was issued. Later, the pilot projects regarding flash flood 
disaster prevention were carried out. Based on the exploration, a set of effective technical systems and management systems for the flash flood disaster prevention were established. With casualty minimization as the primary target, the work of flash flood disaster prevention mainly focused on non-structural measures with the structural measures as supplementary. Based on the experience distilled from the pilot projects, the construction of non-structural measures on the flash flood disaster prevention was carried out comprehensively in 1836 counties. This work is organized and financed by the central government, esp. the Ministry of Water Resources and the Ministry of Finance. It is implemented by local governments. It is one of the activities of overall flood risk management of China. Currently, the completed projects have played a tremendous role in disaster prevention.

In parallel with the development of non-structural measures against flash flood disasters, and in accordance with the decision of the Chinese government, the Ministry of Water Resources and the Ministry of Land and Resources re-formulated the Thematic Plan on the Geological Hazard Control Caused by Flash Flood based on the former NFFCP [10]. Structural measures, non-structural measures and personnel resettlement will be implemented comprehensively and the capacity of flash flood disaster prevention will be improved comprehensively.

\section{Acknowledgments}

The authors are grateful to Qiu Ruitian, Shang Quanmin and Huang Xianlong, who worked in SFDH, for their guidance to write this paper. Great thanks is also given to GuanYuhui and Wang Yanwei for their help in translating this article. Additional thanks is given to three anonymous reviewers for their comments and suggestions.

\section{References}

1. Carpenter, T.M.; Sperfslage, J.A.; Georgakakos, K.P.; et al. National threshold runoff estimation utilizing GIS in support of operational flash flood warning systems. J. Hydrol. 1999, 224, 21-44.

2. Price, C.; Yair, Y.; Mugnai, A.; Lagouvardos, K.; Llasat, M.C.; Michaelides, S. FLASH: A new EU project related to Mediterranean flash floods. Presented at Geophysical Research Abstracts, Vienna, Austria, 2007.

3. Huang, X.L.; Chu, M.H.; Zuo, J.C.; Yang, Y.X. Strengthen the development of non-structural measures on the flash flood disaster prevention in China. China Flood Drought Manage. 2010, 20, 4-6.

4. Editorial Group of NFFCP. National Flash Flood Control Planning; NFFCP: Beijing, China, 2006.

5. Office of State Flood Control and Drought Relief Headquarters. Guideline for the Compilation of Flash Flood Disaster Prevention Plan; SFDH: Beijing, China, 2009.

6. Office of State Flood Control and Drought Relief Headquarters. Technical Requirements on the Development of Warning System for the Flash Flood Disaster Prevention at County Level; SFDH: Beijing, China, 2010.

7. Office of State Flood Control and Drought Relief Headquarters. Guideline for Compiling Implementation scheme of Non-structural Measures Construction for the Flash Flood Disaster Prevention at County Level; SFDH: Beijing, China, 2010. 
8. Office of State Flood Control and Drought Relief Headquarters. National Management Method on Non-structural Measures Construction for the Flash Flood Disaster Prevention at County Level; SFDH: Beijing, China, 2011.

9. Office of State Flood Control and Drought Relief Headquarters; Beijing, China, 2010. Available online: http://www.qgshzh.com (accessed on 19 March 2012).

10. United Editorial Group. Thematic Plan on the Geological Hazard Control Caused by Flash Flood; Beijing, China, 2010.

(C) 2012 by the authors; licensee MDPI, Basel, Switzerland. This article is an open access article distributed under the terms and conditions of the Creative Commons Attribution license (http://creativecommons.org/licenses/by/3.0/). 